\title{
Fabrication and Photoluminiscent Properties of Titanium Oxide Nanotube Arrays
}

\author{
Dong Fang, * Kelong Huang, * Shuqin Liu and Jianhan Huang \\ College of Chemistry \& Chemical Engineering, Central South University, \\ Changsha 410083, People's Republic of China
}

\begin{abstract}
Um arranjo de nanotubos de óxido de titânio alinhados verticalmente foi gerado com sucesso na superfície de um substrato de titânio pela técnica de anodização. Os nanotubos foram caracterizados por microscopia eletrônica de varredura (MEV), difratometria de raios X de pó (DRX), espectroscopia Raman e espectroscopia de fotoluminescência. Os resultados indicam que o tamanho dos nanotubos de óxido de titânio é altamente dependente da voltagem aplicada e que suas propriedades de fotoluminescência são fortemente influenciadas pela estrutura cristalina. Adicionalmente, efeitos quânticos de tamanho estão presentes nas propriedades dos nanotubos de $\mathrm{TiO}_{2}$.
\end{abstract}

An array of vertically aligned titanium oxide nanotubes was successfully grown on the surface of a titanium substrate by the anodization technique. The nanotubes were characterized by scanning electron microscopy (SEM), powder X-ray diffractometry (XRD), Raman spectroscopy and photoluminescence spectroscopy (PL). The results indicate that the size of the titanium oxide nanotube is greatly dependent on the applied voltage, and its photoluminescence properties are strongly influenced by the crystal structure. In addition, it is shown that quantum size effects are present in the optical properties of $\mathrm{TiO}_{2}$ nanotubes.

Keywords: oxides, chemical synthesis, crystal structure, photoluminescent

\section{Introduction}

In recent years, titanium oxide $\left(\mathrm{TiO}_{2}\right)$ has received much attention from researchers owing to its properties including photocatalytic activity. Anatase and rutile are the two main crystalline structures of $\mathrm{TiO}_{2}$, with band gap energies at 3.2 and $3.0 \mathrm{eV}$, respectively. ${ }^{1}$ The photocatalytic activity of $\mathrm{TiO}_{2}$ depends on its surface to volume ratio and crystal structure, and several studies have been performed in order to investigate these issues. ${ }^{2,3}$ In particular, one dimensional $\mathrm{TiO}_{2}$ such as nanotubes is more attractive because of its large specific surface area, which has more reactive sites to absorb and oxidize pollutants such as benzene, phenol, and $p$-chlorophenol. ${ }^{4}$

To produce one dimensional $\mathrm{TiO}_{2}$, a number of methods have been used, such as hydrothermal ${ }^{5}$ and anodic alumina membranes (AAM) methods, ${ }^{6}$ chemical vapor deposition, ${ }^{7}$ and anodic oxidation. ${ }^{8}$ Among these methods, the anodic oxidation is shown to be a powerful and efficient technique. Gong has fabricated the first generation of titania nanotube array by anodization using an aqueous HF-based electrolyte, and $\mathrm{TiO}_{2}$ nanotube (TONT) arrays

*e-mail: csufangdong@gmail.com; klhuang@mail.csu.edu.cn could be grown up to a length of $500 \mathrm{~nm} .{ }^{9}$ The results from Schmuki indicate that the TONT array length can be increased up to $7 \mu \mathrm{m}$ when the $\mathrm{pH}$ of the anodization electrolyte is kept high while remaining acidic. ${ }^{10}$ In 2006 , Grimes reported a new generation of vertically oriented $\mathrm{TiO}_{2}$ nanotubes with length up to $134 \mu \mathrm{m}$ by using various non-aqueous electrolytes. ${ }^{11}$ In our previous work, a TONT array was grown on the surface of a titanium substrate by the anodization technique. ${ }^{12}$ The properties of this TONT array are investigated further in this work.

The photoluminescence (PL) spectrum of $\mathrm{TiO}_{2}$ can be used to study its energy levels and hence can provide information on differences between anatase and rutile electronic structures. ${ }^{13,14}$ Moreover, the PL spectrum of $\mathrm{TiO}_{2}$ is strongly dependent on the surface condition, and hence information on surface properties can be obtained by PL spectroscopy. ${ }^{15}$ To the best of our knowledge, few attention has been paid to optical properties of TONT, especially for the well-organized array formed directly on titanium substrates. In the present work, the photoluminescence properties of $\mathrm{TiO}_{2}$ nanotubes are studied in the processes of phase transformation from anatase to rutile. The origin of the luminescence bands are also studied by in situ photoluminescence spectroscopy. 


\section{Experimental}

Titanium (Ti) foils (99.6\% purity), $0.1 \mathrm{~mm}$ thick, were degreased by sonication in acetone, isopropanol and methanol, and then chemically polished in $\mathrm{H}_{2} \mathrm{O}_{2}(15 \mathrm{wt} \%)$ / $\mathrm{NaOH}\left(0.6 \mathrm{~mol} \mathrm{~L}^{-1}\right)$ solution for $10 \mathrm{~min}$ to form a fresh smooth surface. This procedure was followed by rinsing with deoinized (DI) water and drying in a nitrogen stream. For electrochemical experiments, the samples were contacted and then pressed against an O-ring in an electrochemical cell, leaving $1 \mathrm{~cm}^{2}$ exposed to the electrolyte. The electrochemical setup consisted of a two-electrode configuration with graphite gauze as a counter electrode. All anodization experiments were carried out at room temperature. As an electrolyte for electrochemical experiments we used $1 \mathrm{~mol} \mathrm{~L}^{-1} \mathrm{Na}_{2} \mathrm{SO}_{4}$ solutions with the addition of amounts of $\mathrm{NaF}(1 \mathrm{wt} \%)$. All solutions were prepared from reagent grade chemicals and DI water. The electrochemical treatment consisted of a potential ramp from the open-circuit potential (OCP) to the end potential with a sweep rate of $0.1 \mathrm{~V} \mathrm{~s}^{-1}$, followed by holding the samples for $2 \mathrm{~h} .{ }^{10}$ After the formation of the porous structures, the samples were treated by two methods: (i) ultrasonic cleaning with DI water and drying in a nitrogen stream, followed by a second anodization for $3 \mathrm{~h}$ under the same conditions of the first step; (ii) immediate drying in a nitrogen stream and then intensive ultrasonic cleaning with DI water.

For the structural and morphological characterization of the anodized samples, top and cross-sectional views were recorded by scanning electron microscopy (SEM) using a JSM-SEM. A series of samples were prepared by annealing at different temperatures in ambient atmosphere for $2 \mathrm{~h}$. The crystallographic structures of the samples were determined by powder X-ray diffraction (XRD) using a MXPAHF $\mathrm{X}$-ray diffractometer with $\mathrm{Cu} \mathrm{K}_{\alpha}$ radiation $(\lambda=1.54056 \AA)$. The phase composition of the samples was also determined by Raman spectroscopy (JOBIN YVON) using a He-Ne laser $(632.81 \mathrm{~nm})$ as the light source. The optical absorption properties of the TONT array samples were investigated using a diffuse reflectance UV-Vis spectrometer (Varian, Cary 5000) in the 300-700 $\mathrm{nm}$ wavelength range. The PL spectral measurements were performed on an F-2500 fluorescence spectrophotometer equipped with a Xe lamp as the excitation light source. All the measurements were carried out at room temperature.

\section{Results and Discussion}

Figure 1 shows the top- (a) and cross-view (b) of the porous structure of the sample anodized at $20 \mathrm{~V}$ for $2 \mathrm{~h}$. It is shown that the highly ordered TONT array is composed of nanotubes with average inner diameters of $80 \mathrm{~nm}$.
There are remaining precipitates on the nanotubes. After the formation of the porous structures, the sample was immediately cleaned with DI water in an ultrasonic bath and then dried under nitrogen; its top view is displayed in Figure 2a. By comparing Figure 2a with Figure 1b, it is seen that the SEM image in Figure 2a shows the bottom after wiping off the anodized nanotube array. If the sample is first dried under nitrogen and then cleaned in an ultrasonic bath with DI water, the precipitate on the nanotubes is removed successfully and the uniform nanotube ends are exposed, which is revealed in Figure 2b.

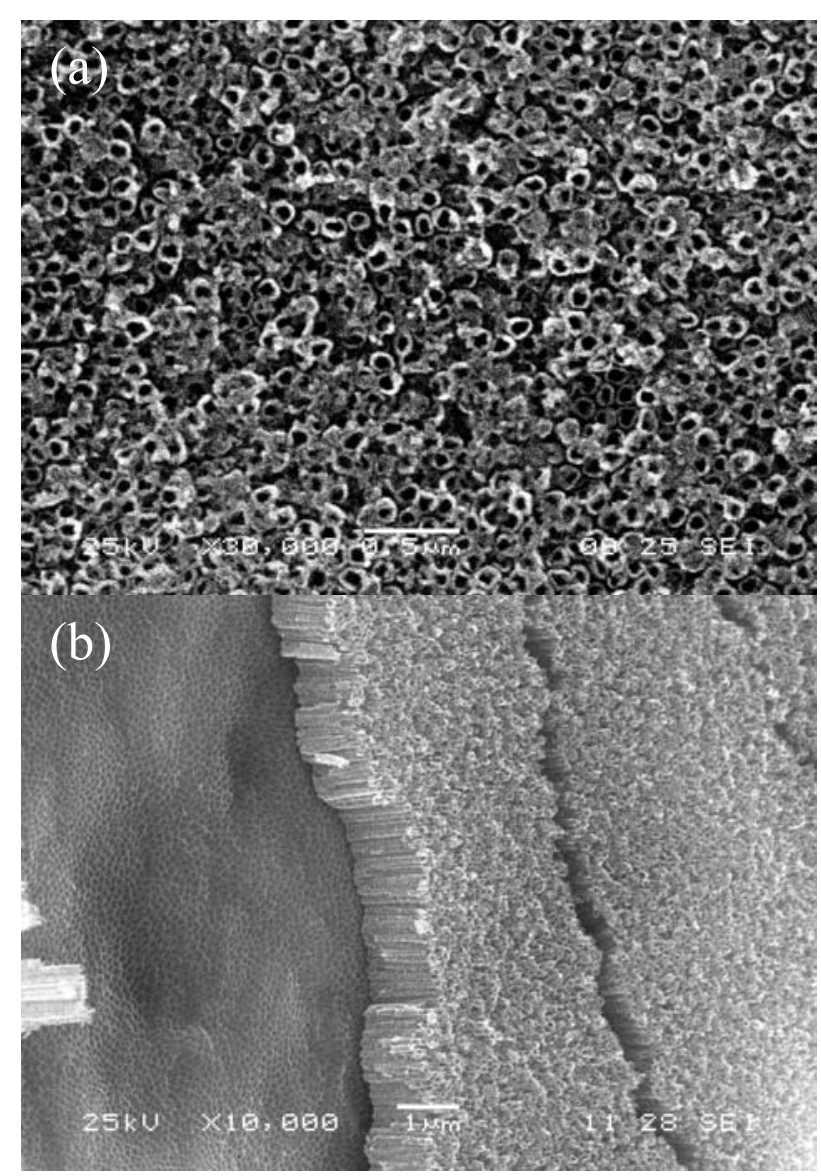

Figure 1. SEM top view (a) and cross-section (b) of TONT arrays formed at $20 \mathrm{~V}$ in 1 wt. $\% \mathrm{NaF}, 1 \mathrm{~mol} \mathrm{~L}^{-1} \mathrm{Na}_{2} \mathrm{SO}_{4}, \mathrm{pH} 4$.

Figure 3 shows the top and cross-view SEM images of the highly dense TONT array morphology prepared using different anodization voltages for $2 \mathrm{~h}$. It can be seen that the sizes of the TONT are about 28 and $52 \mathrm{~nm}$ in inner diameter at 10 and $15 \mathrm{~V}$, respectively. The inner diameter and the wall thickness of the nanotubes increase with increasing anodizing voltage.

Figure 4 shows the top and cross-view of the porous structure obtained by two-step anodization with the applied voltage at $20 \mathrm{~V}$ for $3 \mathrm{~h}$, and it indicates that the 


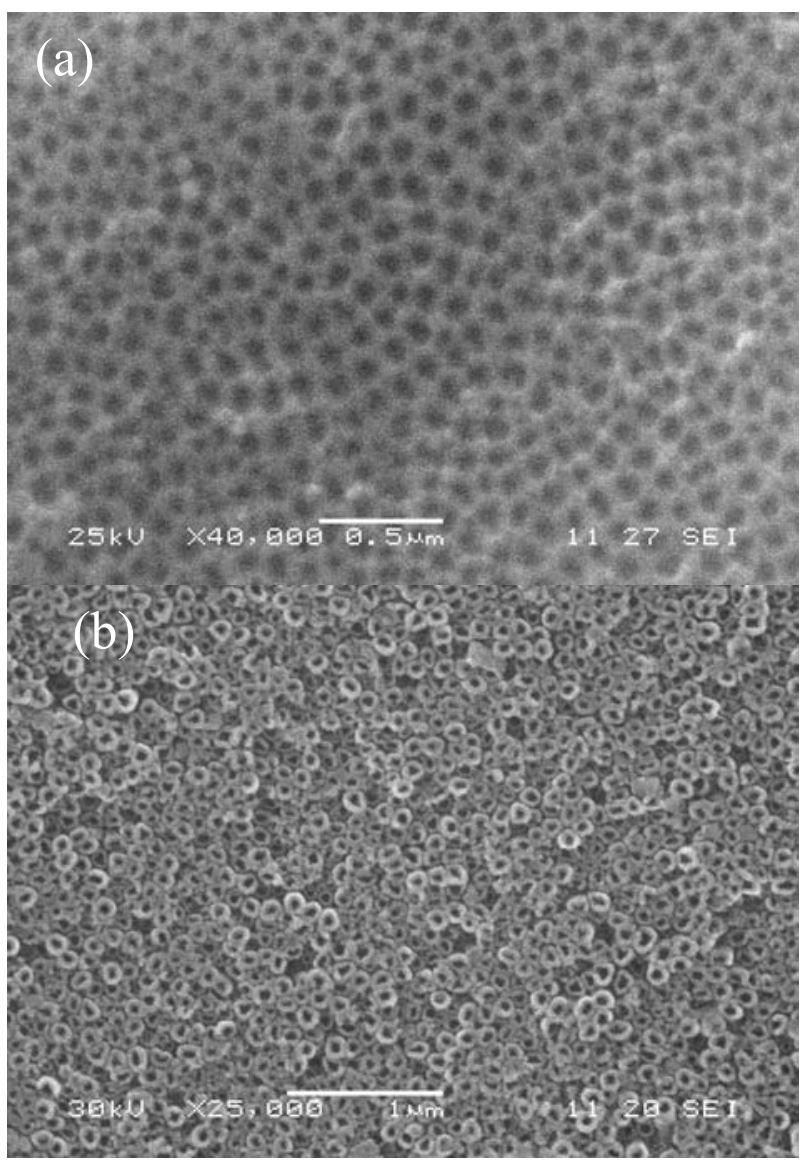

Figure 2. SEM top view of TONT arrays after ultrasonic cleaning: (a) without drying, (b) dried under $\mathrm{N}_{2}$.

porous structure is similar to the one prepared by one-step anodization. The range of tube diameters is reduced only slightly by two-step anodization, and therefore the one-step anodization method was adopted.

Figure 5a gives the X-ray diffraction (XRD) patterns of the TONT arrays heat-treated at different temperatures for $2 \mathrm{~h}$ in dry ambient atmosphere. In the X-ray patterns, the anatase phase appears at $450{ }^{\circ} \mathrm{C}$, which is different from the as-anodized film that is amorphous; only reflections from the $\mathrm{Ti}$ substrate were observed. The rutile phase dominates when the sample is annealed at $700{ }^{\circ} \mathrm{C}$. Paulose reported that the anatase phase is present in the walls, while the rutile phase is not found in the tube walls as the TONT array is annealed at $600{ }^{\circ} \mathrm{C} .{ }^{16}$ The results from Grimes and co-workers ${ }^{17}$ indicate that the geometry constraints imposed by the nanotube walls inhibit the transformation of anatase to rutile. So we can conclude that the rutile crystallites originate in the oxide layer underneath the nanotubes at $700{ }^{\circ} \mathrm{C}$ through nucleation and growth and that the anatase crystallites at the tube walls do not change to rutile due to the constraints imposed by the walls. ${ }^{18,19}$
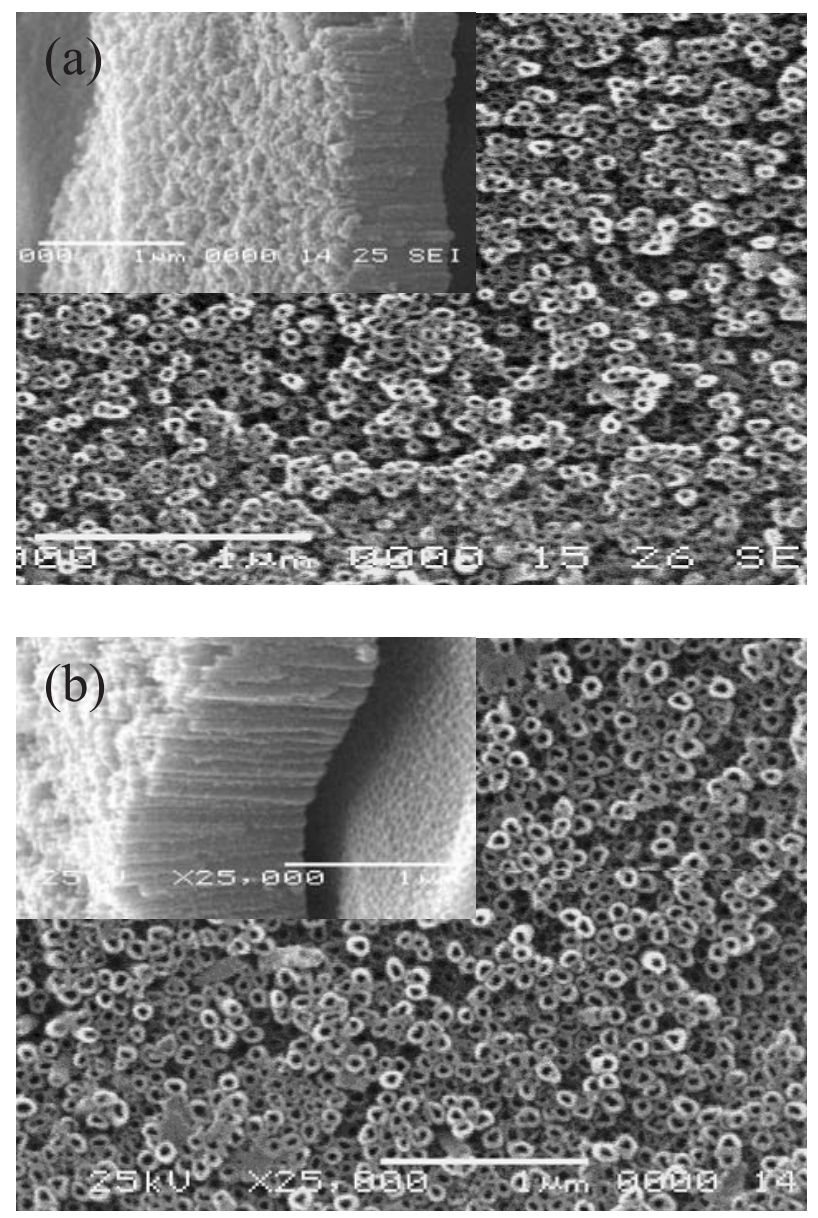

Figure 3. SEM images of TONT arrays (top view) under the anodization voltages of (a) $10 \mathrm{~V}$, (b) $15 \mathrm{~V}$.

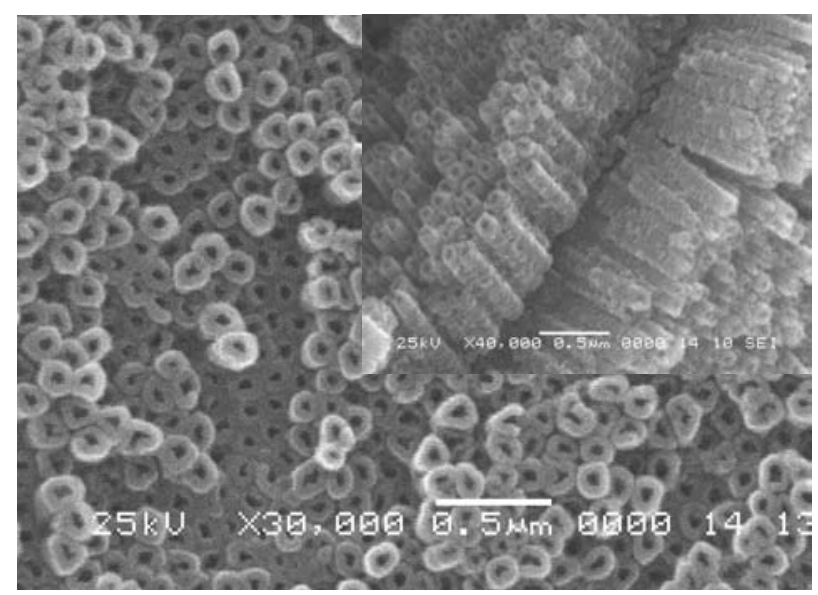

Figure 4. SEM top view and cross-section (insert) of TONT arrays after two-step anodization.

Figure 5b shows the Raman spectra of TONT arrays after calcination at different temperatures ranging from 450 to $800^{\circ} \mathrm{C}$. Raman spectroscopy can be used to demonstrate the effects of the calcination temperature on the phase of TONT arrays on the Ti substrate. The amorphous $\mathrm{TiO}_{2}$ does 

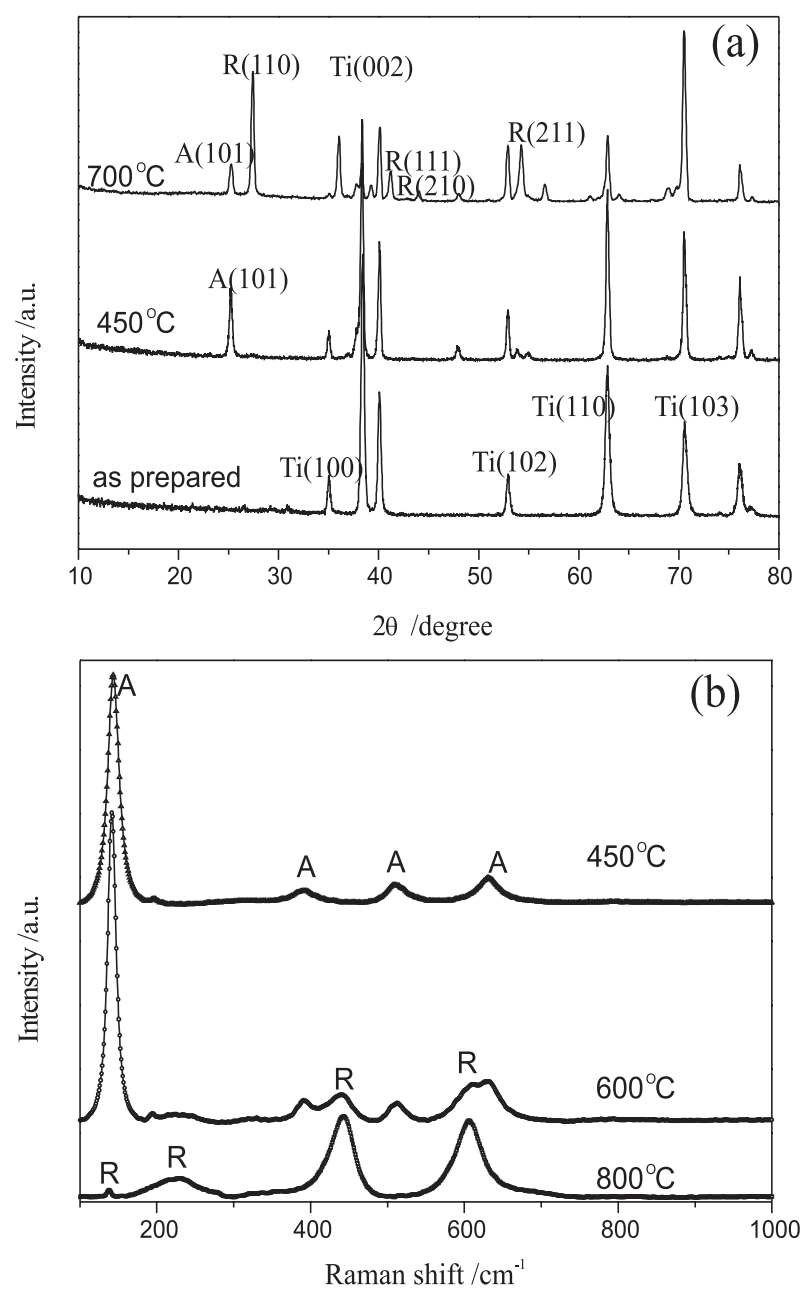

Figure 5. (a) XRD profiles and (b) Raman spectra of TONT arrays after heating at different temperatures for $2 \mathrm{~h}$ in air.

not have well defined Raman peaks. The peaks related to the anatase and rutile are labeled $\mathrm{A}$ and $\mathrm{R}$, respectively. When the sample is calcined at $450{ }^{\circ} \mathrm{C}$, the Raman spectrum presents peaks with wavenumbers of about 144 , $196,387,514$ and $633 \mathrm{~cm}^{-1}$, which can be all assigned to the anatase phase. No peaks either related to rutile or other $\mathrm{TiO}_{2}$ polymorphs were observed for this sample. When the material is calcined at $600{ }^{\circ} \mathrm{C}$, the anatase phase is partially transformed to rutile. The typical peaks of the rutile phase $\left(138,230,443,606 \mathrm{~cm}^{-1}\right)$ are observed and they dominate the Raman spectrum for the sample treated at $800{ }^{\circ} \mathrm{C}$.

The PL emission spectrum is useful to reveal the efficiency of charge carrier trapping, immigration, and transfer. ${ }^{20}$ Figure 6 shows the room temperature PL spectra for $\mathrm{TiO}_{2}$ thin films calcined at $200,300,450$, and $700{ }^{\circ} \mathrm{C}$, respectively, and excited at $310 \mathrm{~nm}$. When the calcined temperature is less than $500{ }^{\circ} \mathrm{C}$, two main emission peaks appear at about 387.0 and $465.0 \mathrm{~nm}$, which are equivalent to 3.20 and $2.67 \mathrm{eV}$, respectively. According to the electronic structure of $\mathrm{TiO}_{2}$, the former peak is assigned to a direct electronic transition from the bottom of the conduction band to the top of the valence band. The electrochemical anodization of Ti may produce oxygen vacancies. ${ }^{21}$ Oxygen vacancies have been considered as the most common defects and usually act as active centers in luminescence processes. ${ }^{22}$ In the present case, oxygen vacancies should be generated because of incomplete crystallization. In addition, the high surface-to-volume ratio of the TONT array should also favor the existence of large quantities of oxygen vacancies. So, we believe that the second peak can be ascribed to electronic transitions mediated by defect levels within the band gap. With the increase of the annealing temperature, the PL intensities increase first, reach a maximum value at $450{ }^{\circ} \mathrm{C}$, and then decrease. The temperature dependent PL data are due to different phase structures and surface microstructures of the annealed samples. The PL emission mainly results from the recombination of excited electrons and holes, and the lower PL intensity indicates the decrease in the recombination rate. When the temperature is $700{ }^{\circ} \mathrm{C}$, the lowest PL intensity is observed due to the $\mathrm{TiO}_{2}$ thin film with better crystallization.

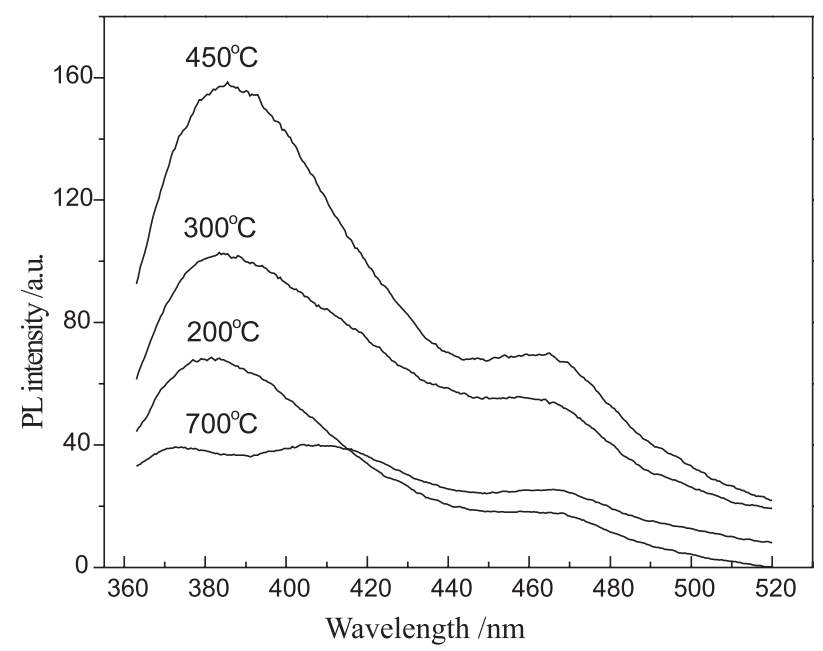

Figure 6. PL spectra of TONT arrays calcined at different temperatures and excited at $310 \mathrm{~nm}$.

The original PL spectra of the sample annealed at $700{ }^{\circ} \mathrm{C}$ and their four Gaussian fitting PL peaks are illustrated in Figure 7. It can be found that the Gaussian curves fit the original PL curves perfectly. Figure 7 shows the band maxima at $3.37 \mathrm{eV}(368.0 \mathrm{~nm}), 3.04 \mathrm{eV}(407.0 \mathrm{~nm}), 2.67 \mathrm{eV}$ $(465.0 \mathrm{~nm})$ and $2.43 \mathrm{eV}(510.5 \mathrm{~nm})$. The first and the second peaks result from the electronic transition from the bottom of the conduction band to the top of the valence band, according to the electronic structure of anatase $(3.2 \mathrm{eV})$ and rutile $(3.0 \mathrm{eV})$, respectively. The nanotubes annealed at $700{ }^{\circ} \mathrm{C}$ collapse and the tubular structure is converted 
to nanowires or nanorods, ${ }^{23}$ which leads to quantum size effect, and hence reduces the blue shifts of the first and the second peaks. The peaks located at $465.0 \mathrm{~nm}$ and $510.5 \mathrm{~nm}$ can be ascribed to the electronic transition originated from defect levels in the band gap. ${ }^{24,25}$

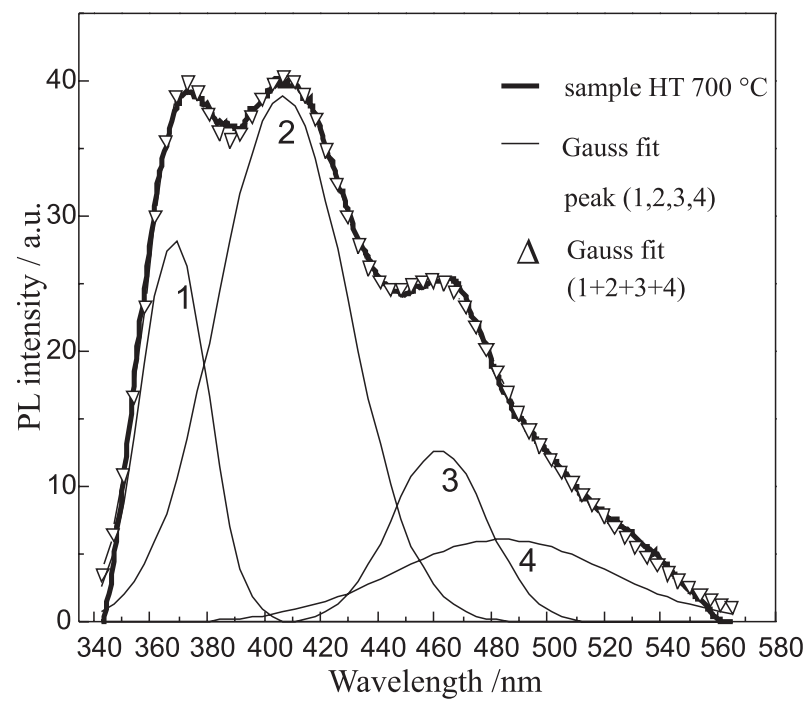

Figure 7. PL spectra and Gaussian fit bands for the sample calcined at $700{ }^{\circ} \mathrm{C}$ and excited at $310 \mathrm{~nm}$.

In order to demonstrate the quantum size effect, the PL spectra and the UV-Vis diffuse absorption spectra of TONT arrays formed at the different anodizing voltages are shown in Figure 8. It is known that the diameter of the tubes and the thickness of the nanotube wall decrease significantly with decreasing potential. Figure 8 a reveals that the peak at $387 \mathrm{~nm}$ shifts toward shorter wavelengths with the decrease of the potential, which could be from the changes in the wall thickness. In Figure $8 b$, the UV-Vis absorption behavior of the TONT arrays prepared at different anodization voltages is distinctly different, and many defect levels can be found from the absorption spectra. The absorption edges shift toward shorter wavelengths with the decrease of the nanotube inner diameter, which might also be a result from the quantum effect due to the thickness of the nanotube wall. However, it is difficult to accurately study the UV-Vis absorption ability of the pure TONT arrays because of the effect of the Ti substrate.

In order to compare the PL spectra of TONT arrays, PL spectra were also recorded at room temperature on analytical grade amorphous $\mathrm{TiO}_{2}$ powder purchased from a commercial company; they are shown in Figure 9. When the temperature is less than $500{ }^{\circ} \mathrm{C}$, two main emission peaks appear at about $395.0 \mathrm{~nm}$ and $465.0 \mathrm{~nm}$, which are similar to those given by the TONT arrays annealed below $500{ }^{\circ} \mathrm{C}$. When the powder is heated to $700{ }^{\circ} \mathrm{C}$ so as to promote the anatase to rutile phase transformation, two main emission peaks appear at about $420.0 \mathrm{~nm}$ and $465.0 \mathrm{~nm}$, therefore different from the observed with the TONT arrays annealed at $700{ }^{\circ} \mathrm{C}$.
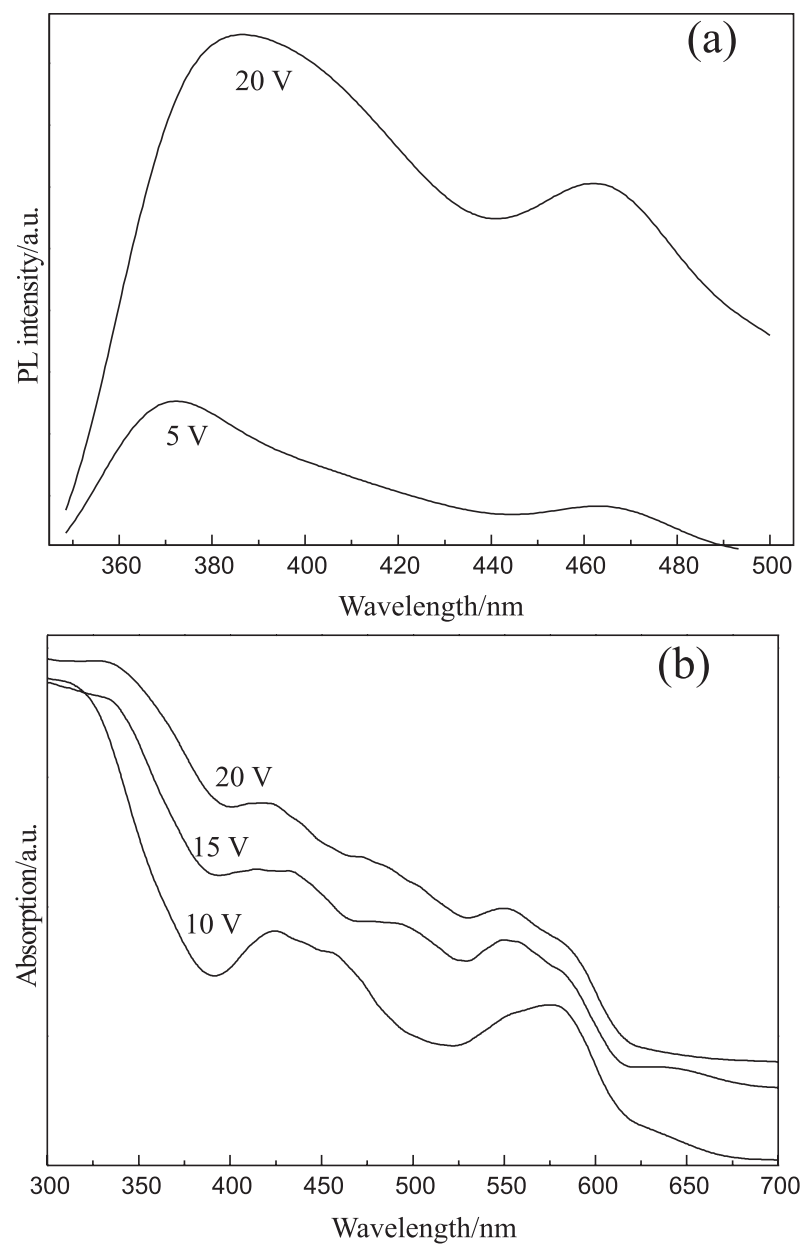

Figure 8. (a) PL spectra of the TONT arrays obtained with different anodization voltages and excited at $310 \mathrm{~nm}$; (b) UV-Vis diffuse absorption spectra of the TONT arrays obtained with different anodization voltages.

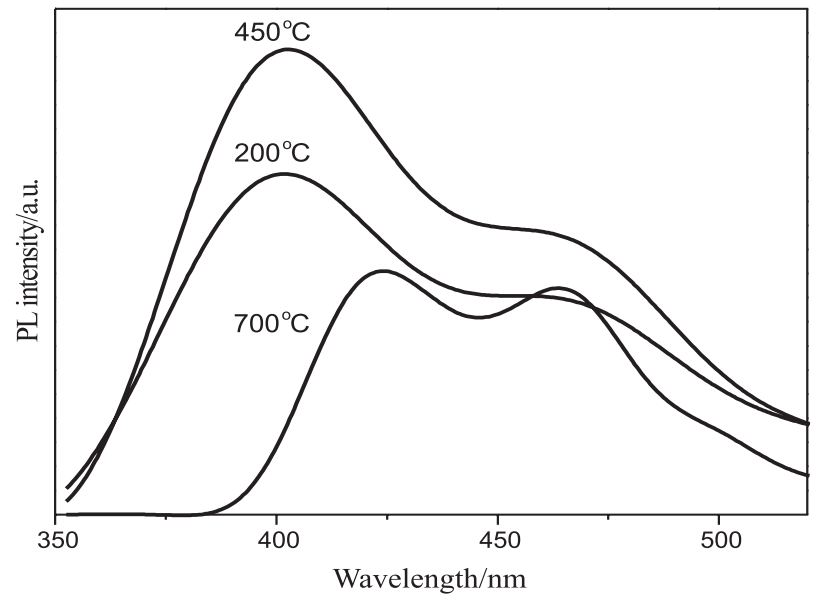

Figure 9. The PL spectra for $\mathrm{TiO}_{2}$ powder calcined at different temperatures and excited at $310 \mathrm{~nm}$. 


\section{Conclusions}

$\mathrm{TiO}_{2}$ nanotube arrays were formed in $\mathrm{Na}_{2} \mathrm{SO}_{4} / \mathrm{NaF}$ electrolytes. The inner diameter and the wall thickness of the nanotubes increased with increasing anodizing voltage. The range of tube diameters was slightly reduced after two-step anodization. XRD and Raman spectra showed that the TONT arrays have different crystalline structures with different calcination temperatures. The photoluminescence of the $\mathrm{TiO}_{2}$ nanotubes was also affected by the calcination temperatures, as two main emission peaks appeared at about 387.0 and $465.0 \mathrm{~nm}$ when the temperature was less than $500{ }^{\circ} \mathrm{C}$, while at $700{ }^{\circ} \mathrm{C}$ the $\mathrm{PL}$ spectra of $\mathrm{TiO}_{2}$ nanotubes showed four peaks at $368.0 \mathrm{~nm}, 407.0 \mathrm{~nm}, 465.0 \mathrm{~nm}$, and $510.5 \mathrm{~nm}$. The two peaks at $368.0 \mathrm{~nm}$ and $407.0 \mathrm{~nm}$ are blue shifted due to quantum size effects.

\section{Acknowledgment}

This work was supported by the Natural Science Foundation of Hunan Province, P. R. China (Grant No. 02JJY3044).

\section{References}

1. Shi, J. Y.; Chen, J.; Feng, Z. C.; Chen, T.; Lian, Y. X.; Wang, X. L.; Li, C.; J. Phys. Chem. C 2007, 111, 693.

2. Ohno, T.; Sarukawa, K.; Tokieda, K.; Matsumura, M.; J. Catal. 2001, 203, 82.

3. Sun, B.; Smirniotis, P. G.; Catal. Today 2003, 88, 49.

4. Quan, X.; Ruan, X. L.; Zhao, H. M.; Chen, S.; Zhao, Y. Z.; Environ. Pollut. 2007, 147, 409.

5. Du, G. H.; Chen, Q.; Che, R. C.; Yuan, Z. Y.; Peng, L. M.; Appl. Phys. Lett. 2001, 79, 3702.

6. Liu, S. Q.; Huang, K. L.; Sol. Energy Mater. Sol. Cells 2005, $85,125$.

7. Wu, J. J.; Yu, C. C.; J. Phys. Chem. B 2004, 108, 3377.

8. Prida, V. M.; Manova, E.; Vega, V.; Hernandez-Velez, M.; Aranda, P.; Pirota, K. R.; Vázquez, M.; Ruiz-Hitzky, E.; J. Magn. Magn. Mater. 2007, 316, 110.
9. Gong, D.; Grimes, C. A.; Varghese, O. K.; Hu, W. C.; Singh, R. S.; Chen, Z.; Dickey, E. C.; J. Mater. Res. 2001, 16, 3331.

10. Macak, J. M.; Tsuchiya, H.; Schmuki, P.; Angew. Chem. Int. Ed. 2005, 44, 2100.

11. Paulose, M.; Shankar, K.; Yoriya, S.; Prakasam, H. E.; Varghese, O. K.; Mor, G. K.; Latempa, T. A.; Fitzgerald, A.; Grimes, C. A.; J. Phys. Chem. B 2006, 110, 16179.

12. Liu, S. Q.; Fang, D.; Li, Z. J.; Huang, K. L.; Chinese J. Inorg. Chem. 2007, 23, 827.

13. Nakajima, H.; Itoh, K.; Murabayashi, M.; Bull. Chem. Soc. Jpn. 2002, 75, 601 .

14. Montoncello, F.; Carotta, M. C.; Cavicchi, B.; Ferroni, M.; Giberti, A.; Guidi, V.; Malagu, C.; Martinelli, G.; Meinardi, F.; J. Appl. Phys. 2003, 94, 1501.

15. Serpone, N.; Lawless, D.; Khairutdinov, R.; J. Phys. Chem. 1995, 99, 16646

16. Paulose, M.; Mor, G. K.; Varghese, O. K.; Shankar, K.; Grimes, C. A.; J. Photochem. Photobiol., A 2006, 178, 8.

17. Cai, Q.; Paulose, M.; Varghese, O. K.; Grimes, C. A.; J. Mater. Res. 2005, 20, 230.

18. Varghese, O. K.; Gong, D. W.; Paulose, M.; Grimes, C. A.; Dickey, E. C.; J. Mater. Res. 2003, 18, 156.

19. Mazali, I. O.; Souza, Filho, A. G.; Viana, B. C.; Filho, J. M.; Alves, O. L.; J. Nanopart. Res. 2006, 8, 141.

20. Li, X. Z.; Li, F. B.; Yang, C. L.; Ge, W. K.; J. Photochem. Photobiol., A 2001, 141, 209.

21. Vanheusden, K.; Warren, W. L.; Seager, C. H.; Tallant, D. R.; Voigt, J. A.; Gnade, B. E.; J. Appl. Phys. 1996, 79, 7983.

22. Gu, F.; Wang, S. F.; Lu, M. K.; Zhou, G. J.; Xu, D.; Yuan, D. R.; J. Phys. Chem. B 2004, 108, 8119.

23. Lee, W. J.; Alhoshan, M.; Smyrl, W. H.; J. Electrochem. Soc. 2006, 153, B499.

24. Li, D.; Ohashi, N.; Hishita, S.; Kolodiazhnyi, T.; Haneda, H.; J. Solid State Chem. 2005, 178, 3293.

25. Jing, L. Q.; Sun, X. J.; Cai, W. M.; Xu, Z. L.; Du, Y. G.; Fu, H. G.; J. Phys. Chem. Solids 2003, 64, 615.

Received: August 9, 2007 Web Release Date: June 16, 2008 